\title{
Cost Analysis for a Supplier in an Inflationary Environment with Stock Dependent Demand Rate for Perishable Items
}

\author{
Madhu Jain, ${ }^{1}$ G. C. Sharma, ${ }^{2}$ and Varsha Rani ${ }^{3}$ \\ ${ }^{1}$ Department of Mathematics, IIT Roorkee, Roorkee 247667, India \\ ${ }^{2}$ Department of Mathematics, IBS, Khandari, Agra 282002, India \\ ${ }^{3}$ Department of Mathematics, St. John's College, Agra 282002, India \\ Correspondence should be addressed to Varsha Rani; versha.mvn@gmail.com
}

Received 11 May 2014; Revised 22 October 2014; Accepted 31 October 2014; Published 18 December 2014

Academic Editor: Jue Wang

Copyright (C) 2014 Madhu Jain et al. This is an open access article distributed under the Creative Commons Attribution License, which permits unrestricted use, distribution, and reproduction in any medium, provided the original work is properly cited.

\begin{abstract}
The present study is concerned with the cost modeling of an inventory system with perishable multi-items having stock dependent demand rates under an inflationary environment of the market. The concept of permissible delay is taken into account. The study provides the cost analysis of inventory system under the decision criteria of time value of money, inflation, deterioration, and stock dependent demand. Numerical illustrations are derived from the quantitative model to validate the results. The cost of inventory and optimal time are also computed by varying different system parameters. The comparison of these results is facilitated by computing the results with neurofuzzy results.
\end{abstract}

\section{Introduction}

Inflation is a very common scenario of a dynamic market which affects a common man and the decision makers equally. The term inflation refers to the increment in the rates of the goods. Most of the inventory models, developed so far, did not include the inflation and time value of the money as parameters of the system. But, during the past two decades, a sudden downfall in the market caused highly inflated rates and decision makers felt the need of considering the inflation an integrated part of an inventory model. There are many items which are subject to decay with respect to time. The concept of deterioration has been incorporated by some researchers in different frameworks (cf. [1-3]). The management of inventory emphasizing on time dependent deterioration with salvage value was discussed by Mishra and Shah [4]. Jain et al. [5] considered the concept of deterioration to develop a deterministic production inventory model with time-varying demand. Manna et al. [6] developed an EOQ model for noninstantaneous deteriorating items. The concept of exponential deterioration was considered by Mahata [7] to develop an EPQ-based inventory model. Xiao and Xu [8] discussed a supply chain with deteriorating items for a vendor managed inventory. Wang et al. [9] optimized a seller's credit period in a supply chain for deteriorating items.

Some notable works in the direction of inventory models with time value of money along with inflation are due to Bose et al. [10], Moon and Lee [11], Chang [12]. Singh and Jain [13] developed a model to study the supplier credits in an inflationary environment when reserve money was available. An inventory model by considering the concepts of inflation, deterioration, and permissible delay in the payments was studied by Jain and Chauhan [14]. Sarkar and Moon [15] analyzed an EPQ model by incorporating the effect of inflation for an imperfect production system. Lubik and Teo [16] presented their views on inflation dynamics. Recently, Gilding [17] discussed inflation to analyze the optimal inventory replenishment schedule.

In various inventory models, it is assumed that the demand rate is independent of the internal factors. But, in real world problems, the demand may be influenced by many internal factors such as price, availability, and season. This phenomenon is known as elasticity of the demand. A few researchers have considered stock dependent demand in their works [18-21]. Stock along with price sensitive demand rates was considered by Jain et al. [22] to develop an EPQ model 
with shortages. Some notable aspects related to EOQ model with stock and price sensitive demand was explored by Mo et al. [23]. The inventory model for deteriorating items was discussed by Ouyang et al. [24], Min et al. [25], and Soni [26] by considering stock dependent demand. Recently, Yang [27] analyzed an inventory model with stock dependent demand rate and holding cost.

In today's business tractions, it is more and more common to see that the buyers are allowed some grace period before they settle the account with the supplier instead of paying for the product just after receiving it. This grace period is known as credit period. After crossing the limit of the grace period, the buyer is likely to pay an interest also. Some notable works in this direction are due to Mandal and Phaujdar [28], Hwang and Shinn [29], Chung and Huang [30], and Chen and Kang [31]. Singhal et al. [32] incorporated the concept of delay in payments to obtain an optimal pricing and ordering policy of retailers incorporating variable holding cost. Liang and Zhou [33] considered the concept of permissible delay in payment for an inventory model with deteriorating items. The joint control of inventory with permissible delay in payments was obtained by Maihami and Abadi [34]. Soni [35] presented optimal replenishment policies for the noninstantaneous deteriorating items considering permissible delay in payment. Recently, a two-warehouse inventory model with permissible delay in payment was developed by Bhunia et al. [36].

The neurofuzzy technique came into existence due to the combination of two commonly used soft computing approaches: fuzzy logic and neural network. Recently, a brief review on applications of neurofuzzy systems was given by Kar et al. [37]. The technique is an emerging powerful soft computing technique which has successfully covered many areas including the performance modeling of electronic goods, hardware and software systems, automobiles, manufacturing/production systems, telecommunication systems, and many more. This hybrid soft computing technique plays an important role for the performance modeling of inventory system but only a very few researchers have employed this technique in the field of inventory control till now. Gumus and Guneri [38] discussed stochastic and fuzzy supply chains. Further, Gumus et al. [39] employed neurofuzzy technique to develop a new methodology for multiechelon inventory system in stochastic and neurofuzzy environments.

This present investigation deals with the credits of the supplier in an inflationary environment when the demand rate for the perishable items is stock dependent. The shortages cause an indispensable loss to the suppliers. In this study, we aim at determining the optimal time when the shortages start so that the undesirable shortages can be avoided within time. The phenomenon of credit period in an inflationary environment for multi-items inventory system makes our study different from others. We have employed neurofuzzy technique to compare our analytical results which is one of the special features of our study. The rest of the paper is organized as follows. In Section 2, model description along with the notations and assumptions is given. The formulation of cost functions along with the computational procedure for obtaining the optimal time and minimum cost is given in Section 3. In Section 4, numerical results are presented to validate the computational procedure. Finally, conclusion is drawn in Section 5.

The noble feature of our investigation is to develop the inventory model with deterioration and stock dependent demand to facilitate the cost and optimal policy by incorporating the concepts of time value of money along with inflation. The concept of controlled deterioration can be realized in many electronic and machining systems. It is noticed that the deterioration can be controlled up to some extent with some preventive maintenance (e.g., by controlling the temperature/humidity of ware houses) or some preservation technology (e.g., polishing and oiling) in case of machining systems. The controlled deterioration rate included in the present inventory model makes our study different from the existing research.

\section{Model Description}

Consider an inventory model with a single supplier who can supply several items to satisfy the customers' demands. The demand of $n$th items is directly proportional to the available stock of each type of item. All the items are prone to deteriorate with a constant rate but the deterioration can be controlled by some preservation technology. The planning horizon is finite and the shortages are completely backlogged. In order to increase the business, the customers are allowed to take a grace period for payment.

2.1. Notations. In order to formulate the mathematical model of the present problem, we use the following notations:

$\alpha_{n}$ : The initial demand for the $n$th item

$\beta_{n}$ : Constant of the inventory at time $t$ for the $n$th item

$Q_{n}(t)$ : The stock available for the $n$th item at time $t$

$m$ : Total number of items

$f$ : Inflation factor

$r$ : Discount rate representing the time value of money

$R$ : Present value of the nominal inflation; that is, $R=$ $f-r$

$I_{\text {en }}$ : Interest rate earned at time $t$ for the $n$th item per rupee/unit time

$i_{e n}: I_{e n}-r$ where $I_{e n}$ is nominal interest at time $t=0$ for $n$th item

$I_{p n}(t)$ : Interest rate paid at time $t$ for the $n$th item per rupee/unit time

$i_{p}: I_{p n}-r$ where $I_{p n}$ is nominal interest paid at time $t=0$ for the $n$th item

$I_{T n}$ : Total interest earned per cycle with inflation for the $n$th item

$P_{T n}$ : Total interest paid per cycle with inflation for the $n$th item

$i_{n}$ : Inventory carrying rate for the $n$th item

$A_{n}$ : Cost of ordering per order for $n$th item 
$T$ : Length of inventory cycle

$T_{1}$ : Length of period with positive stock

$\theta_{n}$ : Rate of deterioration of the $n$th item per unit time $D_{n}(t)$ : Amount of deterioration of the $n$th item per cycle

$\varepsilon$ : Deterioration control rate

$M_{n}$ : Permissible delay in settling the account for the $n$th item

$c_{n}$ : Unit cost per item at time $t=0$ for the $n$th item

$c_{b n}$ : Backorder cost at time $t=0$ for the $n$th item

$C_{b n}$ : Present value of inflated backorder $\operatorname{cost} c_{b}$ for the $n$th item

$C_{D n}$ : Total cost of deterioration for the $n$th item per cycle per unit

$C_{H n}$ : Total holding cost per cycle with inflation for the $n$th item.

2.2. Assumptions. In this subsection, the instantaneous differential equations for the present problem are formulated and solved. For the sake of formulation, some assumptions are considered which are as follows.

(i) The inventory model involves multiple $(m)$ items.

(ii) There is a single supplier in the market.

(iii) The demand of the $n$th $(n=1,2,3, \ldots, m)$ item from the supplier is deterministic and directly proportional to the available stock of the $n$th item in hand of the supplier. Then

$\alpha_{n}+\beta_{n} Q_{n}(t) ; \quad n=1,2, \ldots, m$, where $\alpha_{n}>0,0<\beta_{n}<1$.

(iv) Shortages are allowed and completely backlogged.

(v) Time horizon is finite.

(vi) Backorder starts after time $T_{1}$ which is a decision variable.

(vii) The items deteriorate at a constant rate. The deteriorated items can be neither repaired nor replaced. The items will be withdrawn immediately from the warehouse by the suppliers as they are found to be deteriorated.

(viii) The deterioration of an item can be reduced by using preservation technology.

(ix) $Q_{m}\left(Q_{0}\right)$ denotes the maximum (minimum) inventory level.

Figure 1 represents the inventory model with shortage. The time horizon is finite denoted by $T$ and the shortages start at time $T_{1}$.

The following differential equations represent the instantaneous state of the inventory at any instant of time $t$ for the $n$th $(n=1,2,3, \ldots, m)$ item:

$$
\begin{array}{r}
\frac{d Q_{n}(t)}{d t}+\left(\theta_{n}-\varepsilon\right) I_{n}(t)=-\left(\alpha_{n}+\beta_{n} Q_{n}(t)\right) ; \\
0 \leq t \leq T_{1} .
\end{array}
$$

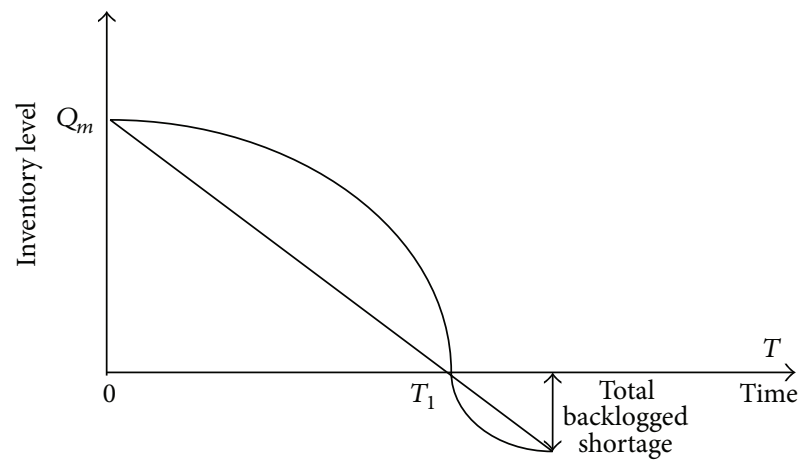

FIGURE 1: Graphical representation of the inventory system.

The boundary conditions are $Q_{n}(t)=Q_{0}$ at time $t=0$ and $Q_{n}(t)=Q_{0}$ at time $t=T_{1}$ which yield

$$
\begin{gathered}
Q_{0}=\frac{\alpha_{n}}{\beta_{n}+\left(\theta_{n}-\varepsilon\right)}\left(-1+e^{\left(\beta_{n}+\left(\theta_{n}-\varepsilon\right)\right)} T_{1}\right) ; \\
Q_{n}(t)=\frac{\alpha_{n}}{\beta_{n}+\left(\theta_{n}-\varepsilon\right)}\left(-1+e^{\left(\beta_{n}+\left(\theta_{n}-\varepsilon\right)\right)\left(T_{1}-t\right)}\right) ; \\
0 \leq t \leq T_{1} .
\end{gathered}
$$

Amount of the $n$th item that deteriorates during one cycle is given by

$$
D_{n}(t)=Q_{0}-\int_{0}^{T_{1}}\left(\alpha_{n}+\beta_{n} Q_{n}(t)\right) d t
$$

It gives

$$
\begin{aligned}
D_{n}(t)= & \frac{\left(\theta_{n}-\varepsilon\right) \alpha_{n}}{\left(\beta_{n}+\left(\theta_{n}-\varepsilon\right)\right)} \\
& \times\left(\frac{e^{\left(\beta_{n}+\left(\theta_{n}-\varepsilon\right)\right) T_{1}}}{\left(\beta_{n}+\left(\theta_{n}-\varepsilon\right)\right)}-\frac{1}{\left(\beta_{n}+\left(\theta_{n}-\varepsilon\right)\right)}-T_{1}\right) .
\end{aligned}
$$

For inflation rate $f$, the continuous time inflation factor for the time period is $e^{f t}$ which means that the $n$th item costs $R s$. $c_{n}$ at time $t=0$ will cost $\left(c_{n} e^{f t}\right)$ at time $t$. For a discount rate $r$, representing the time value of money, the present value of an item at time $t$ is $\left(c_{n} e^{-r t}\right)$. Hence the present value of the inflated price of an item at time $t=0$ is given by

$$
c_{0}=c_{n} e^{(f-r) t}=c_{n} e^{R t} ; \quad R=f-r
$$

Similarly, the present value of the inflated backorder cost $c_{b}$ for $n$th item is given by $C_{n}^{b}$ where

$$
C_{n}^{b}=c_{b n} e^{(f-r) t}=c_{b n} e^{R t}
$$


There are two distinct cases in this type of inventory models:

(1) payment at or before the total depletion of inventory $\left(M \leq T_{1}<T\right)$,

(2) payment after depletion $\left(T_{1}<M\right)$.

Case 1 (payment at or before the total depletion of inventory). Now we obtain various costs involved in the system if the payment is made at or before the total depletion of the inventory.

(i) The Fixed Ordering Cost for the nth Item. Consider

$$
A_{n} R s / \text { order. }
$$

As the ordering is made only once at time $t=0$, the inflation does not affect the ordering cost.

(ii) The Deterioration Cost for the nth Item. Since the initial inventory $Q_{0}$ was purchased at the rate $c_{n}$ without inflation and was sold at a rate $c_{0}$ with inflation during the time period $\left(0, T_{1}\right)$, the deterioration cost for $n$th item is

$$
C_{D n}=c_{n} Q_{0}-\int_{0}^{T_{1}} c_{0}\left(\alpha_{n}+\beta_{n} Q_{n}(t)\right)
$$

which means

$$
\begin{aligned}
C_{D n}= & \frac{c_{n} \alpha}{\beta_{n}+\left(\theta_{n}-\varepsilon\right)}\left(-1+e^{\left(\beta_{n}+\left(\theta_{n}-\varepsilon\right)\right)} T_{1}\right) \\
& -\int_{0}^{T_{1}} c_{n} e^{R t}\left(\alpha_{n}+\beta_{n} Q_{n}(t)\right) \\
C_{D n}= & \frac{c_{n} \alpha_{n}}{\beta_{n}+\left(\theta_{n}-\varepsilon\right)}\left(-1+\frac{\left(\theta_{n}-\varepsilon\right)}{R}\right) \\
& \times\left(1+\frac{R e^{\left(\beta_{n}+\left(\theta_{n}-\varepsilon\right)\right)}}{\beta_{n}+\left(\theta_{n}-\varepsilon\right)-R}\right)-\frac{c_{n} \alpha_{n} e^{R t_{1}}}{\beta_{n}+\left(\theta_{n}-\varepsilon\right)} \\
& \times\left(\frac{\beta_{n}+\left(\theta_{n}-\varepsilon\right)}{R}-\frac{\beta_{n}}{\beta_{n}+\left(\theta_{n}-\varepsilon\right)-R}\right) .
\end{aligned}
$$

(iii) The Holding Cost under Inflation for $n$th Item. It is given by

$$
\begin{gathered}
C_{H n}=i \int_{0}^{T_{1}} c_{0} Q_{n}(t) d t \\
C_{H n}=\frac{i \alpha_{n}}{\beta_{n}+\left(\theta_{n}-\varepsilon\right)} \int_{0}^{T_{1}} c_{n} e^{R t}\left(e^{\left(\beta_{n}+\left(\theta_{n}-\varepsilon\right)\right)\left(T_{1}-t\right)}-1\right) d t \\
C_{H n}=\frac{i \alpha_{n} c}{\beta_{n}+\left(\theta_{n}-\varepsilon\right)}\left(\frac{e^{R T_{1}}}{R-\left(\beta_{n}+\left(\theta_{n}-\varepsilon\right)\right)}-\frac{e^{R T_{1}}}{R}\right. \\
\left.-\frac{e^{\left(\beta_{n}+\left(\theta_{n}-\varepsilon\right) T_{1}\right.}}{R-\left(\beta_{n}+\left(\theta_{n}-\varepsilon\right)\right)}+\frac{1}{R}\right) .
\end{gathered}
$$

(iv) The Interest Payable per Cycle. The interest payable rate at time $t$ is $\left(e^{I_{p n}(t)}-1\right)$. Therefore the interest payable per cycle for the inventory of $n$th item not sold after the due date $M$ is given by

$$
\begin{aligned}
& P_{T n}=c_{n} \int_{M}^{T_{1}}\left(e^{I_{p n}(t)}-1\right) Q_{n}(t) d t \\
& \text { as } Q_{n}(t)=0 \text { for } T_{1} \leq t \leq T \\
& P_{T n}=\frac{c_{n} \alpha_{n}}{\beta_{n}+\left(\theta_{n}-\varepsilon\right)} \\
& \times \int_{M}^{T_{1}}\left(e^{I_{p_{n}}(t)}-1\right)\left(e^{\left(\beta_{n}+\left(\theta_{n}-\varepsilon\right)\right)\left(T_{1}-t\right)}-1\right) d t \\
& P_{\text {Tn }}=\frac{c_{n} \alpha_{n}}{\beta_{n}+\left(\theta_{n}-\varepsilon\right)}\left(\frac{e^{i_{P}}}{i_{P}-\left(\beta_{n}+\left(\theta_{n}-\varepsilon\right)\right)}\right. \\
& +\frac{1}{\beta_{n}+\left(\theta_{n}-\varepsilon\right)}-\frac{e^{i_{P} T_{1}}}{i_{P}}+T_{1} \\
& -\frac{e^{\left(\beta_{n}+\left(\theta_{n}-\varepsilon\right)\right)\left(T_{1}-M\right)+i_{P} M}}{i_{P}-\left(\beta_{n}+\left(\theta_{n}-\varepsilon\right)\right)} \\
& \left.-\frac{e^{\left(\beta_{n}+\left(\theta_{n}-\varepsilon\right)\right)\left(T_{1}-M\right)}}{\beta_{n}+\left(\theta_{n}-\varepsilon\right)}+\frac{e^{i_{P} M}}{i_{P}}-M\right) .
\end{aligned}
$$

The present value of the interest earned at time $t$ is given by $I_{e}(t)=\left(e^{I_{e} t}-1\right) e^{-r t}$. Consider inflated unit cost at time $t$ to be $c_{0}=c_{n} e^{R t}$. The interest earned per cycle from $n$th item, $I_{T n}$, is the interest earned up to time $T_{1}$ and it is given by

$$
\begin{gathered}
I_{T n}=c_{0} \int_{0}^{T_{1}} I_{e}(t)\left(\alpha_{i}+\beta_{i} I_{k}(t)\right) d t \\
I_{T n}=c_{n} \int_{0}^{T_{1}}\left(e^{I_{e}(t)}-1\right) e^{(R-r) t} t \\
\times\left(\alpha_{n}+\frac{\alpha_{n} \beta_{n}}{\beta_{n}+\left(\theta_{n}-\varepsilon\right)}\right. \\
\left.\left.I_{T n}=\alpha_{n} c_{n}\left(\frac{\theta_{n}-\varepsilon}{\beta_{n}+\left(\theta_{n}-\varepsilon\right)}\right) e^{\left(\beta_{n}+\left(\theta_{n}-\varepsilon\right)\left(T_{1}-t\right)\right.}\right)\right) d t \\
\times\left(\frac{T_{1} e^{\left(R+i_{e}\right) T_{1}}}{\left(R+i_{e}\right)}+\frac{e^{\left(R+i_{e}\right) T_{1}}}{\left(R+i_{e}\right)^{2}}-\frac{T_{1} e^{(R-r) T_{1}}}{(R-r)}+\frac{e^{(R-r) T_{1}}}{(R-r)^{2}}\right. \\
\left.+\frac{1}{\left(R+i_{e}\right)^{2}}-\frac{1}{(R-r)^{2}}\right)
\end{gathered}
$$




$$
\begin{aligned}
+\left(\frac{\alpha_{n} c_{n} \beta_{n}}{\beta_{n}+\left(\theta_{n}-\varepsilon\right)}\right)( & \frac{T_{1} e^{\left(R+i_{e}\right) T_{1}}}{\left(i_{e}-\beta_{n}-\left(\theta_{n}-\varepsilon\right)\right)} \\
& -\frac{T_{1} e^{\left(\beta+\theta_{e}\right) T_{1}+R}}{\left(i_{e}-\beta_{n}-\left(\theta_{n}-\varepsilon\right)\right)} \\
& -\frac{e^{\left(R+i_{e}\right) T_{1}}}{\left(i_{e}-\beta_{n}-\left(\theta_{n}-\varepsilon\right)\right)^{2}} \\
& +\frac{e^{\left(\beta+\theta_{e}\right) T_{1}+R}}{\left(i_{e}-\beta_{n}-\left(\theta_{n}-\varepsilon\right)\right)^{2}} \\
& -\frac{T_{1} e^{\left(R-r_{e}\right) T_{1}}}{\left(R-r-\beta_{n}+\left(\theta_{n}-\varepsilon\right)\right)} \\
& \left.+\frac{T_{1} e^{\left(R-r_{e}\right) T_{1}}}{\left(R-r-\beta_{n}+\left(\theta_{n}-\varepsilon\right)\right)^{2}}\right) .
\end{aligned}
$$

(v) The Backorder Cost per Cycle under Inflation. It is

$$
C_{b n}=c_{0} \int_{0}^{T-T_{1}} c_{b n} e^{R\left(T_{1}+t\right)}\left(\alpha_{n}+\beta_{n} Q_{n}(t)\right) d t
$$

The shortage starts at time $T_{1}$ and ends at the end of the cycle, that is, at

$$
\begin{aligned}
& C_{b n}=\alpha_{n} c_{b n}\left(\frac{\theta_{n}}{\beta_{n}+\left(\theta_{n}-\varepsilon\right)}\right)\left(\frac{\left(T-T_{1}\right) e^{R T}}{R}-\frac{e^{R T}}{R^{2}}+\frac{e^{R T_{1}}}{R^{2}}\right) \\
&+\left(\frac{\alpha_{n} c_{b n} \beta_{n}}{\beta_{n}+\left(\theta_{n}-\varepsilon\right)}\right)\left(\frac{\left(T-T_{1}\right) e^{R T+\beta_{n}+\left(\theta_{n}-\varepsilon\right)\left(2 T_{1}-T\right)}}{\left(R-\beta_{n}-\left(\theta_{n}-\varepsilon\right)\right)}\right. \\
&-\frac{\left(T-T_{1}\right) e^{R T+\beta_{n}+\left(\theta_{n}-\varepsilon\right)\left(2 T_{1}-T\right)}}{\left(R-\beta_{n}-\left(\theta_{n}-\varepsilon\right)\right)^{2}} \\
&\left.+\frac{e^{\left(R+\theta_{n}-\varepsilon\right) T_{1}}}{\left(R-\beta_{n}-\left(\theta_{n}-\varepsilon\right)\right)^{2}}\right) .
\end{aligned}
$$

(vi) Total Variable Cost Function. It is

$$
C_{V T}\left(T_{1}, T\right)=\sum_{n=1}^{m}\left(A_{n}+C_{D n}+C_{H n}+P_{T n}-I_{T n}+C_{b n}\right) \text {, }
$$

where $T_{1}$ and $T$ are considered the decision variables. Consider

$$
\begin{aligned}
& C_{V T}\left(T_{1}, T\right) \\
& =\sum_{n=1}^{m}\left(A_{n}+\frac{c_{n} \alpha_{n}}{\beta_{n}+\left(\theta_{n}-\varepsilon\right)}\left(-1+\frac{\left(\theta_{n}-\varepsilon\right)}{R}\right)\right. \\
& \times\left(1+\frac{R e^{\left(\beta_{n}+\left(\theta_{n}-\varepsilon\right)\right)}}{\left(\beta_{n}+\left(\theta_{n}-\varepsilon\right)\right)-R}\right)-\frac{c_{n} \alpha_{n} e^{R t_{1}}}{\left(\beta_{n}+\left(\theta_{n}-\varepsilon\right)\right)} \\
& +\left(\frac{\left(\theta_{n}-\varepsilon\right)}{R}-\frac{\beta_{n}}{\left(\beta_{n}+\left(\theta_{n}-\varepsilon\right)\right)-R}\right) \\
& \times \frac{i \alpha_{n} c}{\left(\beta_{n}+\left(\theta_{n}-\varepsilon\right)\right)} \\
& \times\left(\frac{e^{R T_{1}}}{R-\left(\beta_{n}+\left(\theta_{n}-\varepsilon\right)\right)}-\frac{e^{R T_{1}}}{R}\right. \\
& \left.-\frac{e^{\left(\beta_{n}+\left(\theta_{n}-\varepsilon\right)\right) T_{1}}}{R-\left(\beta_{n}+\left(\theta_{n}-\varepsilon\right)\right)}+\frac{1}{R}\right) \\
& +\frac{c \alpha_{n}}{\left(\beta_{n}+\left(\theta_{n}-\varepsilon\right)\right)} \\
& \times\left(-\frac{e^{R T_{1}}}{R}+\frac{1}{R}-\frac{e^{\left(\beta_{n}+\left(\theta_{n}-\varepsilon\right)\right) T_{1}}}{R-\left(\beta_{n}+\left(\theta_{n}-\varepsilon\right)\right)}\right. \\
& -\frac{e^{i_{p}}}{i_{P}-\left(\beta_{n}+\left(\theta_{n}-\varepsilon\right)\right)}+\frac{1}{\left(\beta_{n}+\left(\theta_{n}-\varepsilon\right)\right)} \\
& -\frac{e^{i_{P} T_{1}}}{i_{P}}+T_{1}-\frac{e^{\left(\beta_{n}+\left(\theta_{n}-\varepsilon\right)\right)\left(T_{1}-M\right)+i_{P} M}}{i_{P}-\left(\beta_{n}+\left(\theta_{n}-\varepsilon\right)\right)} \\
& \left.-\frac{e^{\left(\beta_{i}+\left(\theta_{i}-\varepsilon\right)\right)\left(T_{1}-M\right)}}{\left(\beta_{i}+\left(\theta_{i}-\varepsilon\right)\right)}+\frac{e^{I_{P} M}}{I_{P}}-M\right) \\
& -\alpha_{i} c\left(\frac{\left(\theta_{i}-\varepsilon\right)}{\left(\beta_{i}+\left(\theta_{i}-\varepsilon\right)\right)}\right) \\
& \times\left(\frac{T_{1} e^{\left(R+i_{e}\right) T_{1}}}{\left(R+i_{e}\right)}+\frac{e^{\left(R+i_{e}\right) T_{1}}}{\left(R+i_{e}\right)^{2}}-\frac{T_{1} e^{(R-r) T_{1}}}{(R-r)}+\frac{e^{(R-r) T_{1}}}{(R-r)^{2}}\right. \\
& \left.+\frac{1}{\left(R+i_{e}\right)^{2}}-\frac{1}{(R-r)^{2}}\right)-\left(\frac{\alpha_{n} c_{n} \beta_{n}}{\left(\beta_{n}+\left(\theta_{n}-\varepsilon\right)\right)}\right) \\
& -\left(\frac{T_{1} e^{\left(R+i_{e}\right) T_{1}}}{\left(i_{e}-\left(\beta_{i}+\left(\theta_{i}-\varepsilon\right)\right)\right)}-\frac{T_{1} e^{\left(\left(\beta_{i}+\left(\theta_{i}-\varepsilon\right)\right)\right) T_{1}+R}}{\left(i_{e}-\left(\beta_{i}+\left(\theta_{i}-\varepsilon\right)\right)\right)}\right. \\
& -\frac{e^{\left(R+i_{e}\right) T_{1}}}{\left(i_{e}-\left(\beta_{i}+\left(\theta_{i}-\varepsilon\right)\right)\right)^{2}} \\
& +\frac{e^{\left(\left(\beta_{n}+\left(\theta_{n}-\varepsilon\right)\right)\right) T_{1}+R}}{\left(i_{e}-\left(\beta_{n}+\left(\theta_{n}-\varepsilon\right)\right)\right)^{2}} \\
& -\frac{T_{1} e^{(R-r) T_{1}}}{\left(R-r-\left(\beta_{n}+\left(\theta_{n}-\varepsilon\right)\right)\right)}
\end{aligned}
$$




$$
\begin{array}{r}
\left.+\frac{T_{1} e^{(R-r) T_{1}}}{\left(R-r-\left(\beta_{n}+\left(\theta_{n}-\varepsilon\right)\right)\right)^{2}}\right) \\
\times \alpha_{n} c_{b}\left(\frac{\theta_{n}}{\left(\beta_{n}+\left(\theta_{n}-\varepsilon\right)\right)}\right) \\
\times\left(\frac{\left.\left(T-T_{1}\right) e^{R T}-\frac{e^{R T}}{R^{2}}+\frac{e^{R T_{1}}}{R^{2}}\right)}{R}\right) \\
+\left(\frac{\alpha_{n} c_{b} \beta_{n}}{\left(\beta_{n}+\left(\theta_{n}-\varepsilon\right)\right)}\right) \\
\times\left(\frac{\left(T-T_{1}\right) e^{R T+\left(\beta_{n}+\left(\theta_{n}-\varepsilon\right)\right)\left(2 T_{1}-T\right)}}{\left(R-\left(\beta_{n}+\left(\theta_{n}-\varepsilon\right)\right)\right)}\right. \\
-\frac{\left(T-T_{1}\right) e^{R T+\left(\beta_{n}+\left(\theta_{n}-\varepsilon\right)\right)\left(2 T_{1}-T\right)}}{\left(R-\left(\beta_{n}+\left(\theta_{n}-\varepsilon\right)\right)\right)^{2}} \\
\left.\left.+\frac{e^{(R+\theta) T_{1}}}{\left(R-\left(\beta_{n}+\left(\theta_{n}-\varepsilon\right)\right)\right)^{2}}\right)\right)
\end{array}
$$

Case 2 (payment after the total depletion of inventory; that is, $\left.T_{1}<M\right)$. The deterioration cost $C_{D}$, the holding cost $C_{H}$, and the backlog cost $C_{b}$ are the same as for Case 1 . However the interest paid $P_{T}$ for this case is 0 as the supplier can pay in full at the end of permissible delay, $M$. The interest earned per cycle is the interest earned during the positive inventory period plus the interest earned from cash invested during the time period $\left(T_{1}, M\right)$ after the inventory is exhausted. Then

$$
\begin{aligned}
& I_{T}=c_{0} \int_{0}^{T_{1}} I_{e}(t)(\alpha+\beta I(t)) d t \\
& +\left(e^{i_{e}\left(M-T_{1}\right)}-1\right) \int_{0}^{T_{1}} c_{0} t(\alpha+\beta I(t)) d t \\
& I_{T}=\alpha C\left(\frac{\theta}{\beta+\theta}\right)\left(\frac{T_{1} e^{\left(R+i_{e}\right) T_{1}}}{\left(R+i_{e}\right)}+\frac{e^{\left(R+i_{e}\right) T_{1}}}{\left(R+i_{e}\right)^{2}}-\frac{T_{1} e^{(R-r) T_{1}}}{(R-r)}\right. \\
& \left.+\frac{e^{(R-r) T_{1}}}{(R-r)^{2}}+\frac{1}{\left(R+i_{e}\right)^{2}}-\frac{1^{1}}{(R-r)^{2}}\right) \\
& +\left(\frac{\alpha C \beta}{\beta+\theta}\right)\left(\frac{T_{1} e^{\left(R+i_{e}\right) T_{1}}}{\left(R+i_{e}-\beta-\theta\right)}-\frac{e^{\left(\beta+\theta_{e}\right) T_{1} 1}}{\left(R+i_{e}-\beta-\theta\right)^{2}}\right. \\
& -\frac{e^{\left(R+i_{e}\right) T_{1}}}{\left(R+i_{e}-\beta-\theta\right)^{2}}+\frac{e^{\left(\beta+\theta_{e}\right) T_{1}}}{(R-r-\beta-\theta)^{2}} \\
& \left.-\frac{T_{1} e^{\left(R-r_{e}\right) T_{1}}}{(R-r-\beta-\theta)}+\frac{e^{\left(R-r_{e}\right) T_{1}}}{(R-r-\beta-\theta)^{2}}\right) \\
& +\alpha C\left(E^{I_{E}\left(m-t_{1}\right)}-1\right)\left(\frac{T_{1} e^{R T_{1}}}{(R)}-\frac{e^{R T_{1}}}{(R)^{2}}+\frac{1}{(R)^{2}}\right)
\end{aligned}
$$

$$
\begin{aligned}
& \times\left(\frac{\theta}{\beta+\theta}\right)+\left(\frac{\alpha C \beta}{\beta+\theta}\right) \\
& \times\left(\frac{T_{1} e^{R T_{1}}}{(R-\beta-\theta)}-\frac{e^{R T_{1}}}{(R-\beta-\theta)^{2}}+\frac{e^{(\beta+\theta) T_{1}}}{(R-\beta-\theta)^{2}}\right) .
\end{aligned}
$$

\section{Computational Procedure}

We consider the case of multiple cycles per year so that there are $N$ complete cycles during the time horizon $T$. Hence $N T=1$. The inflation and time value of money exist for each cycle of replenishment, so we need to consider the effect over the time horizon NT. So the total cost during the total time is given by

$$
\begin{aligned}
C_{T}\left(T_{1}, T\right) & =C_{V T} \times\left(1+e^{R T}+e^{2 R T} \cdots+e^{(N-1) R T}\right) \\
& =C_{V T} \times\left(\frac{1-e^{R}}{1-e^{R T}}\right) .
\end{aligned}
$$

Here, the decision variables for these equations are $T_{1}$ and $T$. The optimal value of these decision variables can be determined with the help of the following differential equations:

$$
\frac{\partial C_{T}\left(T_{1}, T\right)}{\partial T_{1}}=0, \quad \frac{\partial C_{T}\left(T_{1}, T\right)}{\partial T}=0 .
$$

After determining these values, the cost function can be determined from (16) and (18).

The solutions of (19) will give the optimal value of $T_{1}$ and $T$, that is, $T_{1}^{*}$ and $T^{*}$. The minimum total cost $C_{T}^{*}\left(T_{1}, T\right)$ at $T_{1}=T_{1}^{*}$ and $T=T^{*}$ is computed as

$$
\begin{gathered}
\frac{\partial^{2} C_{T}\left(T_{1}, T\right)}{\partial T_{1}^{2}}<0, \quad \frac{\partial^{2} C_{T}\left(T_{1}, T\right)}{\partial T^{2}}<0 \\
\left(\frac{\partial^{2} C_{T}\left(T_{1}, T\right)}{\partial T_{1}^{2}}\right)\left(\frac{\partial^{2} C_{T}\left(T_{1}, T\right)}{\partial T^{2}}\right)-\left(\frac{\partial^{2} C_{T}\left(T_{1}, T\right)}{\partial T_{1} \partial T}\right)^{2}>0 ;
\end{gathered}
$$

$T_{1}=T_{1}^{*}, T=T^{*}$ are satisfied.

\section{Numerical Results}

For the sensitivity analysis of the cost function with respect to various system parameters, we have developed a computer program using Mathematica software. Firstly, we analyse the effects of varying parameters on the cost function as given in Section 3. Further, we compare these numerical results with the neurofuzzy results. Unlike classical analytical approaches, this soft computing approach is capable of dealing with fuzzy information to handle real time problems. We fix the variables as $i=1, R=0.1, c_{1}=C=10, M=2, c_{b 1}=20, A_{1}=500$, $\alpha_{1}=0.5, \beta_{1}=0.06, \theta_{1}=0.01, c_{1}=10, i_{e}=0.13, \theta=0.01$, $i_{p}=0.15, r=0.2, i=0.8$, and $\varepsilon=0.3 \theta$ and obtain the numerical results. 
TABLE 1: Linguistic values of the membership function for various input parameters.

\begin{tabular}{lcl}
\hline Input variables & $\begin{array}{c}\text { Number of membership } \\
\text { functions }\end{array}$ & Linguistic variables \\
\hline & & (i) Low \\
$\theta$ & 4 & (ii) Average \\
& (iii) High \\
& (iv) Very high \\
\hline
\end{tabular}

\subsection{Effect of Parameters on the Cost Function}

(i) Effect of Initial Demand $(\alpha)$. Table 2 depicts that an increased initial demand $\alpha$ causes an earlier end of the positive stock time which consequently decreases the length of the total time considered for the model. As the supplier has to pay a shortage cost after the positive stock time and loss of goodwill in the market, he will place an order earlier and it would lessen the total time $T$. But this situation will certainly cost more as he will have to first invest for the sufficient stock as the demand is stock dependent and only after that he can earn more profits.

(ii) Effect of Coefficient ( $\beta$ ). An increased $\beta$ means increased demand as $\beta$ is the coefficient of the inventory level at time $t$ in the demand rate. This means that if the supplier has sufficient inventory, he will have more demand and also increased value of $\beta$. But as the supplier has sufficient stock with him, he will order after a longer time and it will result in increment in the cost. This fact is quite clear in Table 3.

(iii) Effect of Inflation Rate (R). Higher inflation rate compels the supplier to stock the items in advance which increases the positive stock times $T_{1}$ and $T$ along with the cost. This result is drawn from Table 4.

(iv) Effect of Holding and Backlog Cost. Tables 5 and 6 represent that increased holding cost and backlogging cost result in increased cost for the supplier which matches with real time situations.

(v) Effect of Deterioration Rate $(\theta)$. Figures 3 and 4 show that at first small increments in deterioration rate do not affect the supplier so much and he has increment in positive stock time. But as the rate becomes higher his stock replenishes sooner and he has to place order earlier. As deterioration rate increases, the cost also increases which is as we expect.

4.2. Comparison of Analytical Results with ANFIS Results. We have obtained the cost function $T, T_{1}$ by varying the parameters, namely, the deterioration rate $(\theta)$. Treating $\theta$ as linguistic variables in the context of fuzzy systems, the respective inference systems are built up by considering $\theta$ to be input values. We use the Gaussian function as the membership functions for these input parameters. The linguistic values of the membership functions are provided in Table 1.
TABLE 2: Effect of variation in $\alpha$ on cost.

\begin{tabular}{lccc}
\hline$\alpha$ & $T_{1}$ & $T$ & $C_{T}$ \\
\hline .2 & 4.9427 & 12.2787 & 1117.84 \\
.4 & 4.2196 & 10.6359 & 1678.20 \\
.6 & 3.9523 & 10.0286 & 2238.61 \\
.8 & 3.8124 & 9.71079 & 2799.04 \\
1.0 & 3.7262 & 9.51498 & 3359.16 \\
\hline
\end{tabular}

TABLE 3: Effect of variation in $\beta$ on cost.

\begin{tabular}{lccc}
\hline$\beta$ & $T_{1}$ & $T$ & $C_{T}$ \\
\hline .01 & 2.16314 & 2.98596 & 118.74 \\
.03 & 2.83601 & 5.70964 & 642.69 \\
.05 & 3.06597 & 9.34532 & 1340.79 \\
.07 & 4.86386 & 11.1262 & 3227.46 \\
.09 & 4.95471 & 10.4944 & 5561.50 \\
\hline
\end{tabular}

TABLE 4: Effect of variation in $R$ on cost.

\begin{tabular}{cccc}
\hline$R$ & $T_{1}$ & $T$ & $C_{T}$ \\
\hline .2 & - & - & - \\
.3 & 3.5352 & - & - \\
.4 & 5.8345 & 15.5451 & 1917.03 \\
.5 & 6.1272 & 17.2886 & 3087.70 \\
.6 & 7.6404 & 19.7854 & 4504.81 \\
\hline
\end{tabular}

TABLE 5: Effect of variation in $c_{1}$ on cost.

\begin{tabular}{cccc}
\hline$c_{1}$ & $T_{1}$ & $T$ & $C_{T}$ \\
\hline 11 & 4.1822 & 10.6766 & 2096.01 \\
12 & 4.3222 & 11.0326 & 2232.91 \\
13 & 4.4587 & 11.3795 & 2371.45 \\
14 & 4.5919 & 11.7182 & 2508.68 \\
15 & 4.7222 & 12.0494 & 2647.63 \\
\hline
\end{tabular}

TABLE 6: Effect of variation in $c_{b}$ on cost.

\begin{tabular}{cccc}
\hline$c_{b}$ & $T_{1}$ & $T$ & $C_{T}$ \\
\hline 21 & 3.9391 & 10.0571 & 1961.71 \\
22 & 3.8471 & 9.8281 & 1963.89 \\
23 & 3.7613 & 9.6025 & 1966.18 \\
24 & 3.6811 & 9.3974 & 1968.56 \\
25 & 3.6059 & 9.2051 & 1971.01 \\
\hline
\end{tabular}

Figure 2 displays the shape of the corresponding membership function. A comparative study of analytical results and neurofuzzy results is facilitated in Figures 3-4. The figures show almost collinear graphs for both analytical and ANFIS results which imply that our results based on ANFIS are very close to the analytical results and are at par with the analytical results.

Summarizing, we can say that if the credit period ends after the complete replenishment, the supplier has to pay less. So it is economical to delay in the settlement of accounts to the last moment of the permissible delay in payments 


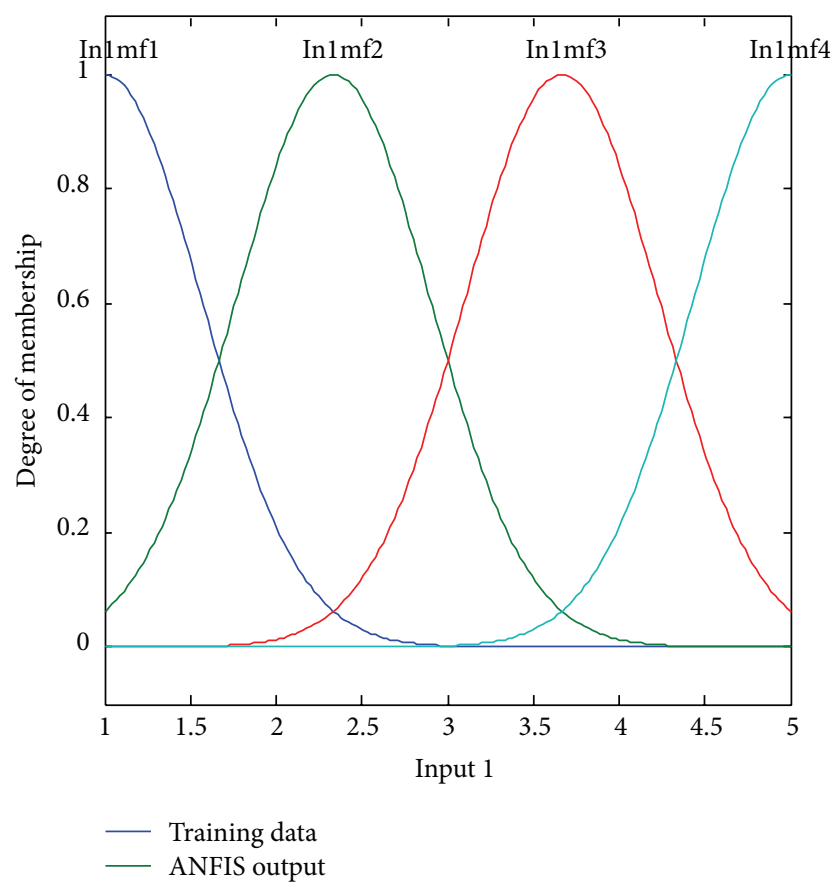

FIGURE 2: Gaussian membership function for input parameter $\theta$.

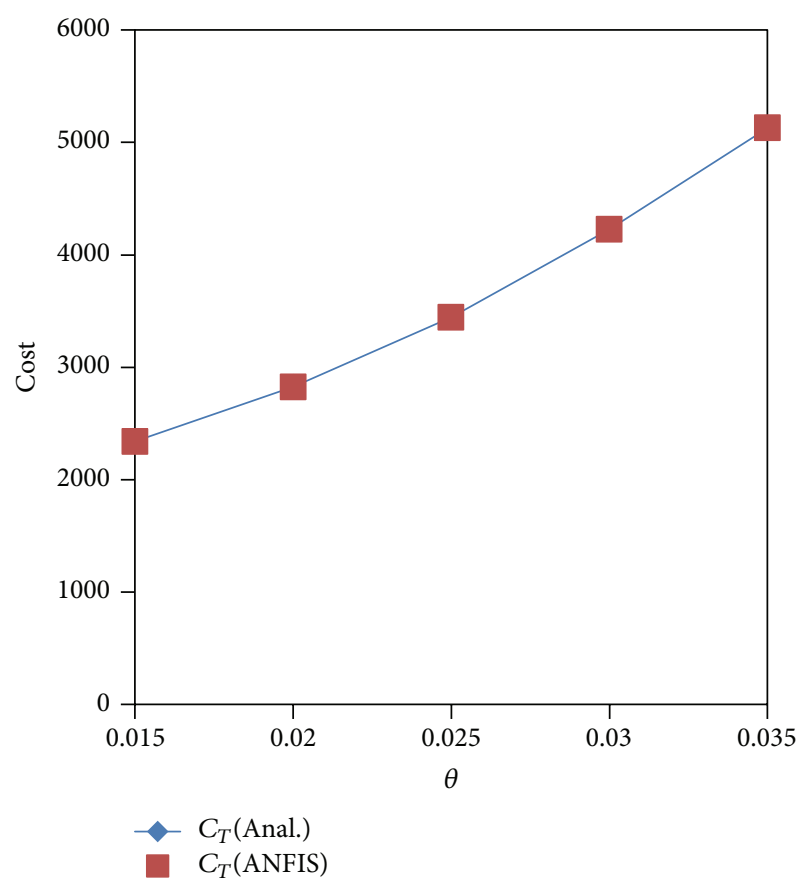

FIgURe 3: Cost by varying $\theta$.

\section{Conclusion}

We have developed an inventory model to examine the supplier's credits in an inflationary environment with a stock dependent demand for perishable multi-items. The stock dependent demand rates along with permissible delay in payment are commonly seen in many businesses as such

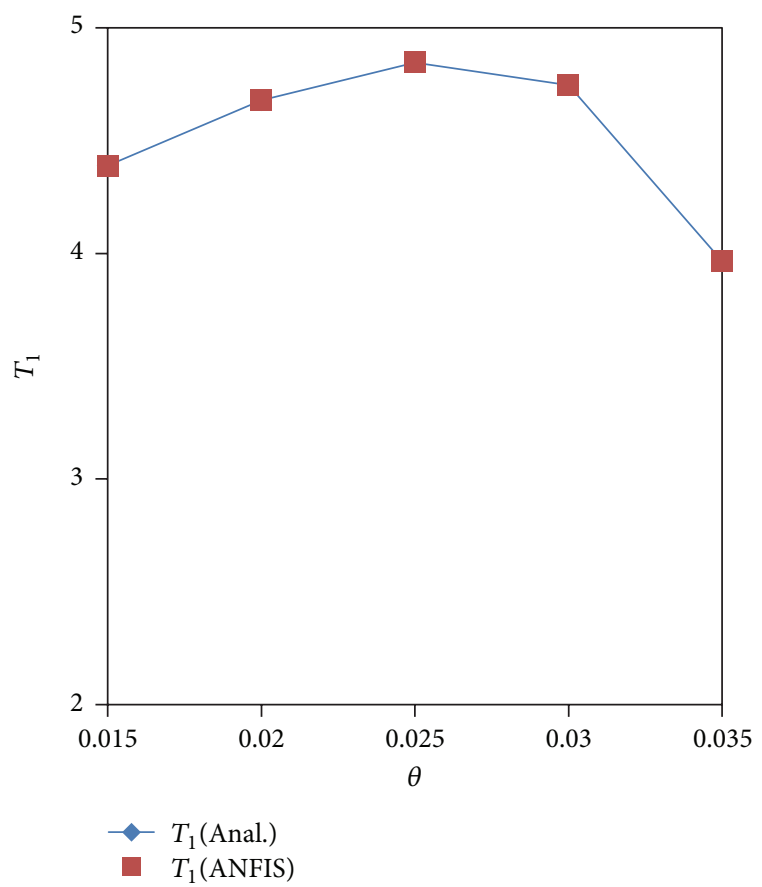

FIgURE 4: $T_{1}$ by varying $\theta$.

incorporation of such realistic features brings our study closer to real world inventory problems. Deterioration may cause very heavy loss and reduction to the profit incurred because of the credit period. That is why we have considered the controlled deterioration rate. Till now the researches are mainly confined to single item. In the present study, we provide the optimal time to place an order for multi-items so that the undesirable cost of the shortages may be reduced and the supplier may avail the maximum benefit of the credit period and the minimum loss due to unavoidable deterioration. The results derived from this model may prove very helpful to the decision makers, suppliers, and the manufacturer in the present scenario of rising prices.

The research can be further be extended as a two or three level supply chain management may also be a topic of keen interest for the researchers as well as practitioners.

\section{Conflict of Interests}

The authors declare that there is no conflict of interests regarding the publication of this paper.

\section{References}

[1] N. H. Shah and Y. K. Shah, "Literature survey on inventory models for deteriorating items," Economic Annals, vol. 44, pp. 221-237, 2000.

[2] S. K. Goyal and B. C. Giri, “The production-inventory problem of a product with time varying demand, production and deterioration rates," European Journal of Operational Research, vol. 147, no. 3, pp. 549-557, 2003.

[3] P. C. Yang and H. M. Wee, "A win-win strategy for an integrated vendor buyer deteriorating inventory system," in Proceedings 
of the 10th International Conference CMAM2 (MMA '05), Mathematical and Computer Modelling, pp. 541-546, Trakai, Lithuania, 2005.

[4] P. Mishra and N. H. Shah, "Inventory management of time dependent deteriorating items with salvage value," Applied Mathematical Sciences, vol. 2, no. 13-16, pp. 793-798, 2008.

[5] M. Jain, G. C. Sharma, and R. Sharma, "A deterministic production inventory model for deteriorating items with timevarying demand and shortage-dependent partial backlogging," International Journal of Information and Computing Science, vol. 11, no. 2, pp. 11-17, 2008.

[6] S. K. Manna, C. C. Lee, and C. Chiang, "EOQ model for noninstantaneous deteriorating items with time-varying demand and partial backlogging," International Journal of Industrial and Systems Engineering, vol. 4, no. 3, pp. 241-254, 2009.

[7] G. C. Mahata, "An EPQ-based inventory model for exponentially deteriorating items under retailer partial trade credit policy in supply chain," Expert Systems with Applications, vol. 39, no. 3, pp. 3537-3550, 2012.

[8] T. Xiao and T. Xu, "Coordinating price and service level decisions for a supply chain with deteriorating item under vendor managed inventory," International Journal of Production Economics, vol. 145, no. 2, pp. 743-752, 2013.

[9] W. C. Wang, J. T. Teng, and K. R. Lou, "Seller's optimal credit period and cycle time in a supply chain for deteriorating items with maximum lifetime," European Journal of Operational Research, vol. 232, no. 2, pp. 315-321, 2014.

[10] S. Bose, A. Goswami, and K. S. Choudhuri, "An EOQ model for deteriorating items with linear time-dependent demand rate and shortages under inflation and time discounting," Journal of the Operational Research Society, vol. 27, pp. 213-224, 1995.

[11] I. Moon and S. Lee, "The effects of inflation and time-value of money on an economic order quantity model with a random product life cycle," European Journal of Operational Research, vol. 125 , no. 3, pp. 588-601, 2000.

[12] C. T. Chang, "An EOQ model with deteriorating items under inflation when supplier credits linked to order quantity," International Journal of Production Economics, vol. 88, no. 3, pp. 307316, 2004.

[13] S. R. Singh and R. Jain, "Understanding supplier credits in an inflationary environment when reserve money is available," International Journal of Operational Research, vol. 6, no. 4, pp. 459-474, 2009.

[14] M. Jain and D. Chauhan, "Inventory model with deterioration, inflation and permissible delay in payments," Arya Bhatta Journal of Mathematics \& Informatics, vol. 2, pp. 165-174, 2010.

[15] B. Sarkar and I. Moon, "An EPQ model with inflation in an imperfect production system," Applied Mathematics and Computation, vol. 217, no. 13, pp. 6159-6167, 2011.

[16] T. A. Lubik and W. L. Teo, "Inventories, inflation dynamics and the New Keynesian Phillips curve," European Economic Review, vol. 56, no. 3, pp. 327-346, 2012.

[17] B. H. Gilding, "Inflation and the optimal inventory replenishment schedule within a finite planning horizon," European Journal of Operational Research, vol. 234, no. 3, pp. 683-693, 2014.

[18] B. C. Giri, S. Pal, A. Goswami, and K. S. Chaudhuri, "An inventory model for deteriorating items with stock-dependent demand rate," European Journal of Operational Research, vol. 95, no. 3, pp. 604-610, 1996.
[19] T. K. Datta and K. Paul, "An inventory system with stockdependent, price-sensitive demand rate," Production Planning and Control, vol. 12, no. 1, pp. 13-20, 2001.

[20] N. K. Mahapatra and M. Maiti, "Multi objective inventory models of multi items with quality and stock dependent demand and stochastic deterioration," Advanced Modeling and Optimization, vol. 7, no. 1, pp. 69-84, 2005.

[21] H. K. Alfares, "Inventory model with stock-level dependent demand rate and variable holding cost," International Journal of Production Economics, vol. 108, no. 1-2, pp. 259-265, 2007.

[22] M. Jain, G. C. Sharma, and S. Rathore, "Economic production quantity models with shortage, price and stock-dependent demand for deteriorating items," International Journal of Engineering, Transactions A: Basics, vol. 20, no. 2, pp. 159-168, 2007.

[23] J. Mo, F. Mi, F. Zhou, and H. Pan, "A note on an EOQ model with stock and price sensitive demand," Mathematical and Computer Modelling, vol. 49, no. 9-10, pp. 2029-2036, 2009.

[24] L.-Y. Ouyang, K.-S. Wu, and C.-T. Yang, "Retailer's ordering policy for non-instantaneous deteriorating items with quantity discount, stock-dependent demand and stochastic backorder rate," Journal of the Chinese Institute of Industrial Engineers, vol. 25, no. 1, pp. 62-72, 2008.

[25] J. Min, Y. W. Zhou, and J. Zhao, "An inventory model for deteriorating items under stock-dependent demand and twolevel trade credit," Applied Mathematical Modelling, vol. 34, no. 11, pp. 3273-3285, 2010.

[26] H. N. Soni, "Optimal replenishment policies for deteriorating items with stock sensitive demand under two-level trade credit and limited capacity," Applied Mathematical Modelling, vol. 37, no. 8, pp. 5887-5895, 2013.

[27] C. T. Yang, "An inventory model with both stock-dependent demand rate and stock-dependent holding cost rate," International Journal of Production Economics, vol. 155, pp. 214-221, 2014.

[28] B. N. Mandal and S. Phaujdar, "Some EOQ models under permissible delay in payments," International Journal of Management Science, vol. 5, no. 2, pp. 99-109, 1989.

[29] H. Hwang and S. W. Shinn, "Retailer's pricing and lot sizing policy for exponentially deteriorating products under the condition of permissible delay in payments," Computers and Operations Research, vol. 24, no. 6, pp. 539-547, 1997.

[30] K. J. Chung and Y. F. Huang, "The optimal cycle time for EPQ inventory model under permissible delay in payments," International Journal of Production Economics, vol. 84, no. 3, pp. 307-318, 2003.

[31] L. H. Chen and F. S. Kang, "Integrated vendor-buyer cooperative inventory models with variant permissible delay in payments," European Journal of Operational Research, vol. 183, no. 2, pp. 658-673, 2007.

[32] S. Singhal, Urvashi, and U. Sharma, "Optimal pricing and ordering policy of retailers with variable holding cost under delay in payments," International Transactions in Mathematics, Science and Computers, vol. 2, no. 1, pp. 177-184, 2009.

[33] Y. Liang and F. Zhou, "A two-warehouse inventory model for deteriorating items under conditionally permissible delay in payment," Applied Mathematical Modelling, vol. 35, no. 5, pp. 2221-2231, 2011.

[34] R. Maihami and I. N. Abadi, "Joint control of inventory and its pricing for non-instantaneously deteriorating items under permissible delay in payments and partial backlogging," Mathematical and Computer Modelling, vol. 55, no. 5-6, 17221733 pages, 2012. 
[35] H. N. Soni, "Optimal replenishment policies for noninstantaneous deteriorating items with price and stock sensitive demand under permissible delay in payment," International Journal of Production Economics, vol. 146, no. 1, pp. 259-268, 2013.

[36] A. K. Bhunia, C. K. Jaggi, A. Sharma, and R. Sharma, "A two-warehouse inventory model for deteriorating items under permissible delay in payment with partial backlogging," Applied Mathematics and Computation, vol. 232, pp. 1125-1137, 2014.

[37] S. Kar, S. Das, and P. K. Ghosh, "Applications of neuro fuzzy systems: a brief review and future outline," Applied Soft Computing Journal, vol. 15, pp. 243-259, 2014.

[38] A. T. Gumus and A. F. Guneri, "A multi-echelon inventory management framework for stochastic and fuzzy supply chains," Expert Systems with Applications, vol. 36, no. 3, pp. 5565-5575, 2009.

[39] A. T. Gumus, A. F. Guneri, and F. Ulengian, "A new methodology for multi-echelon inventory management in stochastic and neuro-fuzzy environments," International Journal of Production Economics, vol. 128, no. 1, pp. 248-260, 2010. 


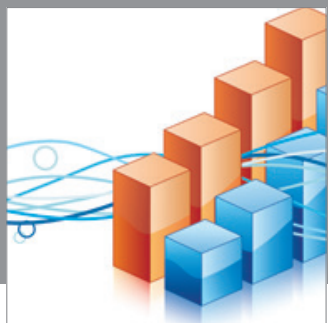

Advances in

Operations Research

mansans

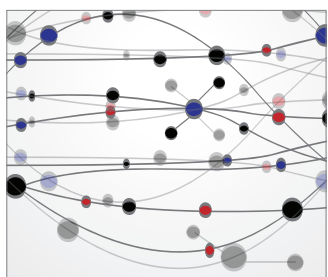

The Scientific World Journal
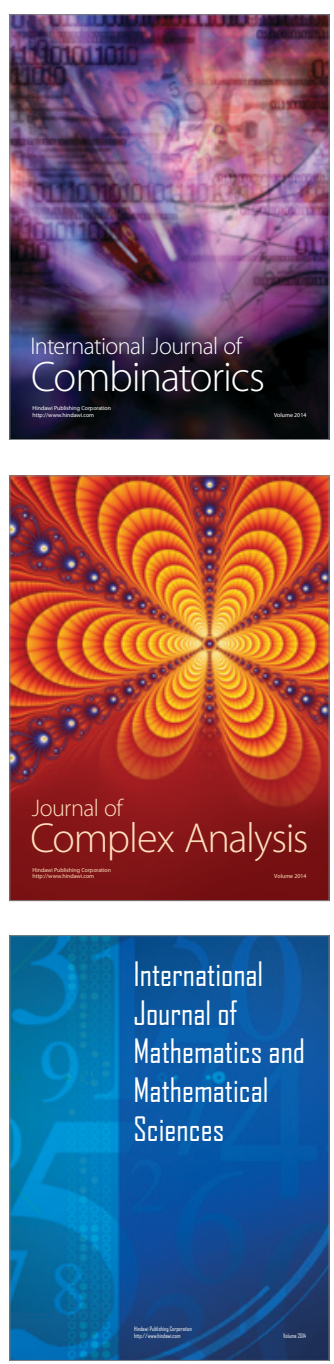
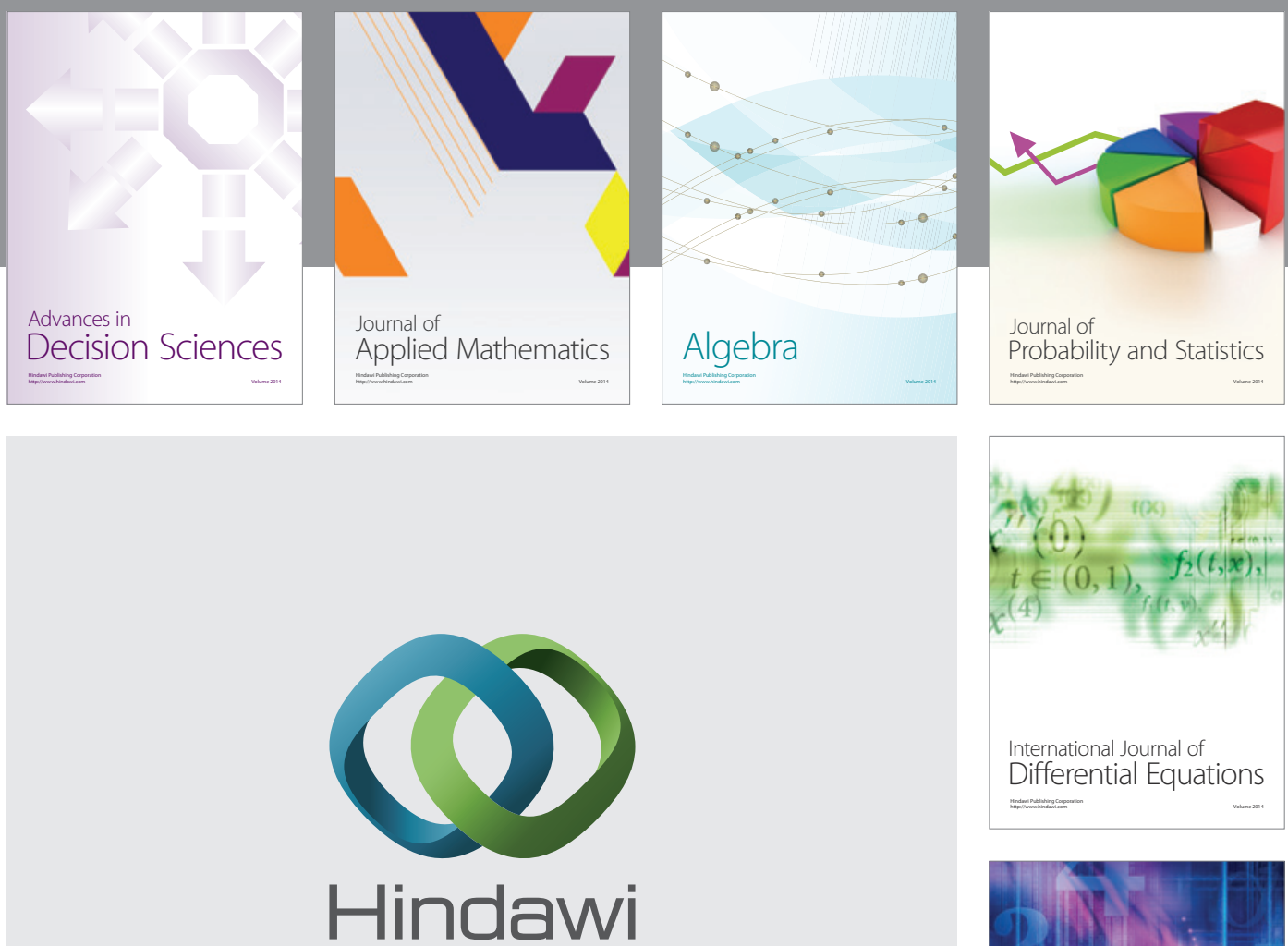

Submit your manuscripts at http://www.hindawi.com
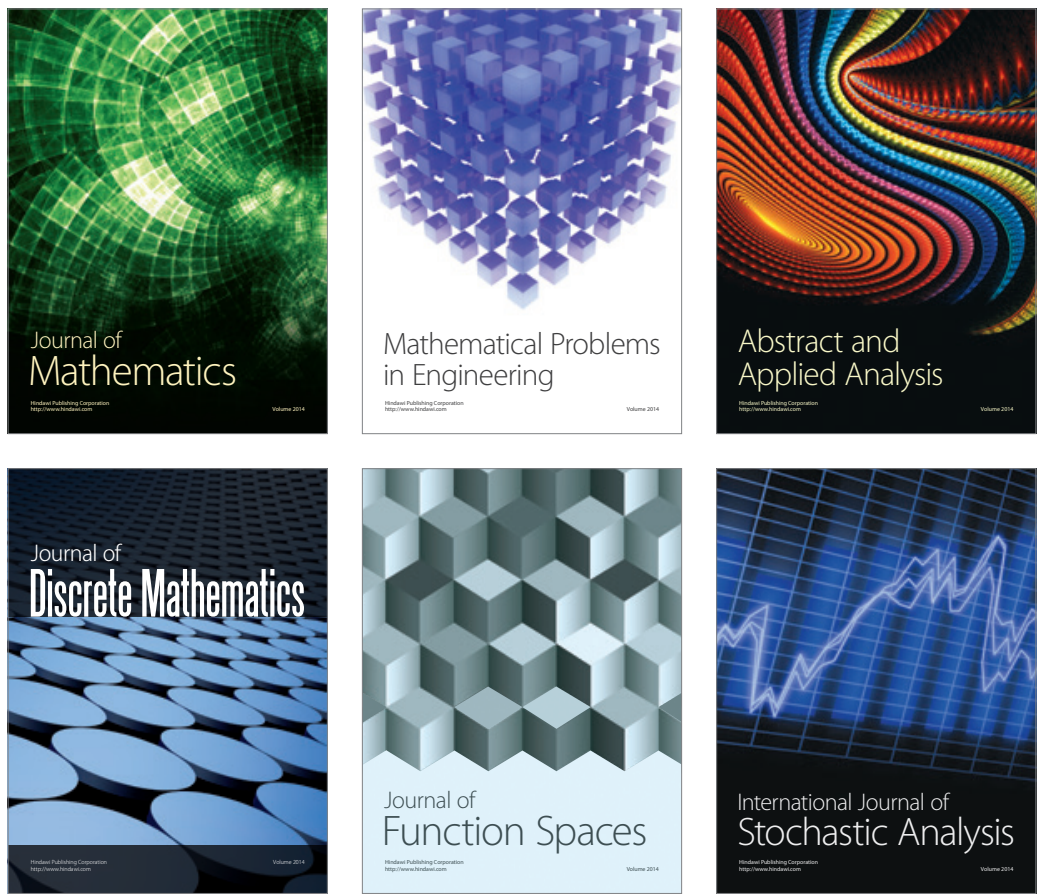

Journal of

Function Spaces

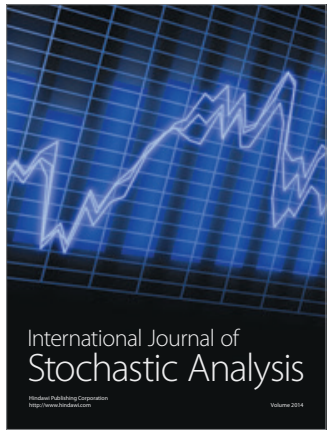

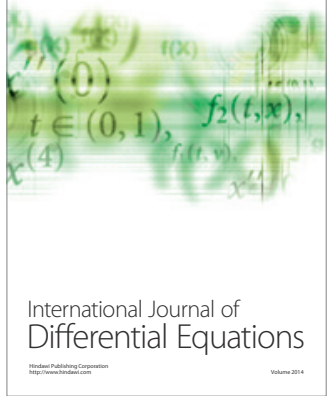
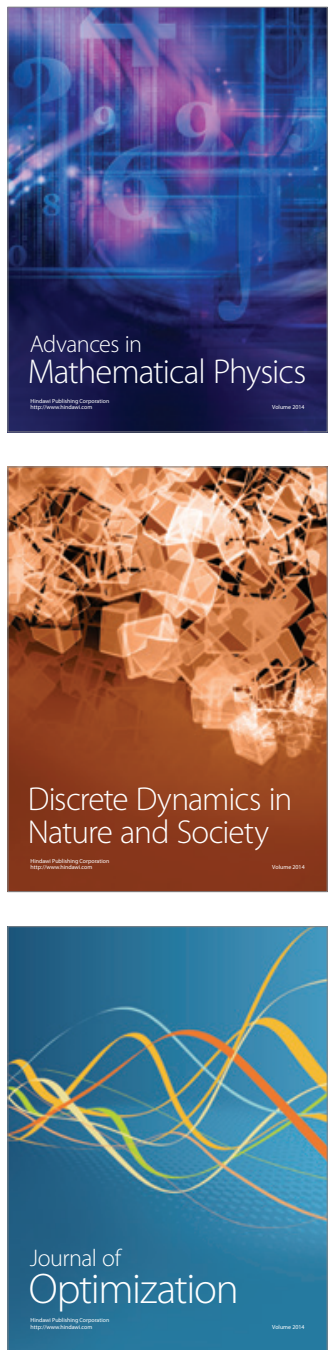